\title{
CURQVignette
}

\section{Enhancing Global Citizenship through Student Research Presentations}

Rachel Core

Stetson University,rcore@stetson.edu

The semester-long course Population, Society, and Environment (SOCI 215R) meets a general education elective in environmental responsibility at Stetson University, a private, predominantly undergraduate institution in central Florida. The course has no prerequisites, so it attracts students from a variety of majors. The course examines how demographic change leads to environmental change, as well as how demographic and environmental changes prompt social change. The class analyzes processes such as the health and mortality transition, fertility transition, migration, and urbanization on a global scale. Students reflect on how these processes affect the environment and on the interventions they can make in their own lives to promote sustainability.

Previous evaluations emphasized that students wanted a more high-impact, experiential learning component. The author drew on her previous experience as a study abroad professional to meet this request. For spring 2016, an optional, half-unit, spring break seminar to Shanghai was designed as a "field trip" for the class. Eight students joined this seminar, including two senior sociology majors, two junior environmental science majors, two sophomore sociology majors, a freshman environmental science major, and an MBA student. These students had taken or were enrolled in either 215R or Introduction to Sociology (101S).

As the largest city in the world's most populous country, Shanghai highlights the relationships among demographic, environmental, and social change in sharp relief. From a practical perspective, it also offers a safe and accessible option for students who do not speak Chinese. The study abroad provider, CET, was enlisted for help in implementing ideas for the program.

The study abroad course was based on the best practices of the Association of American Colleges \& Universities (AAC\&U) for faculty-led programs (Donnelly-Smith 2009). It included visits by representatives from nongovernmental organizations (NGOs) addressing social problems caused by demographic change (such as a lack of schools for migrant children) and visits to an organic farm, a power company that increasingly draws from renewable sources, and a factory that manufactures electric vehicles. Consistent with the environmental theme of the course and its intent to engage students with the local environment, public transportation was used for all but one outing. Shanghai's extensive subway system made a big impression on students, half of whom had no previous experience with public transportation.

Although the length of the program precluded a full-length research project involving a proposal and a test of hypotheses, students did make an initial foray into applied sociological analysis, based on their own observations. Students received the syllabus, which articulated the course readings and requirements, at the beginning of the spring semester. Three weeks before departure, students also attended an orientation session on course expectations and logistics. Attendance of all learning activities in Shanghai was mandatory and allowed students to become participant observers. Students' written work and oral presentations were based on their field notes from meetings with visitors and site visits.

During the nine-day seminar and the week immediately following, students submitted five reflection pieces on topics pertaining to the course. Reflection pieces required students to engage with the readings, to use theoretical lenses and concepts from SOCI $101 \mathrm{~S}$ and $215 \mathrm{R}$, and to include observational evidence to support their arguments. Students were asked to write one piece on morning observations at a local park-which allowed for reflection on health and agingbut they chose the topics of their other pieces. Student subjects included accessible transportation, consumerism, and the meaning of organic.

Nine days after their return to the United States, students met individually with the author to discuss the reflection piece that would be developed into an eight-minute research presentation. Requirements for research presentations included use of four peer-reviewed sources as well as the inclusion of ethnographic field notes and photographic evidence from Shanghai. Presentations were done in $215 \mathrm{R}$ as the semester-long course transitioned between units on urbanization and sustainability. Shanghai seminar students asked their peers to consider important questions such as how to develop values regarding the use of resources and how the values of people in developing countries with large populations may differ from their own. Students in 215R asked questions of the presenters.

Students quickly drew connections between the clothing made from recycled polymers, which was worn by staff at a Buddhist sustainability organization in Shanghai, and the gowns made from similar materials that would be used in Stetson's graduation ceremony. On a deeper level, students from both the study abroad seminar and the longer class began to reconsider the meaning of sustainability and their responsibilities as global citizens. As the course progressed, students calculated their carbon footprint and articulated changes they might make to live more sustainably. As 
